\title{
Planetary Organic Chemistry and the Origins of Biomolecules
}

\author{
Steven A. Benner, Hyo-Joong Kim, Myung-Jung Kim, and Alonso Ricardo \\ Foundation for Applied Molecular Evolution and The Westheimer Institute for Science and Technology, \\ Gainesville, Florida 32601 \\ Correspondence: sbenner@ffame.org
}

\begin{abstract}
Organic chemistry on a planetary scale is likely to have transformed carbon dioxide and reduced carbon species delivered to an accreting Earth. According to various models for the origin of life on Earth, biological molecules that jump-started Darwinian evolution arose via this planetary chemistry. The grandest of these models assumes that ribonucleic acid (RNA) arose prebiotically, together with components for compartments that held it and a primitive metabolism that nourished it. Unfortunately, it has been challenging to identify possible prebiotic chemistry that might have created RNA. Organic molecules, given energy, have a well-known propensity to form multiple products, sometimes referred to collectively as "tar" or "tholin." These mixtures appear to be unsuited to support Darwinian processes, and certainly have never been observed to spontaneously yield a homochiral genetic polymer. To date, proposed solutions to this challenge either involve too much direct human intervention to satisfy many in the community, or generate molecules that are unreactive "dead ends" under standard conditions of temperature and pressure. Carbohydrates, organic species having carbon, hydrogen, and oxygen atoms in a ratio of 1:2:1 and an aldehyde or ketone group, conspicuously embody this challenge. They are components of RNA and their reactivity can support both interesting spontaneous chemistry as part of a "carbohydrate world," but they also easily form mixtures, polymers and tars. We describe here the latest thoughts on how on this challenge, focusing on how it might be resolved using minerals containing borate, silicate, and molybdate, inter alia.
\end{abstract}

Interesting organic chemistry occurs throughout the cosmos, including in presolar nebulae (see the article in this collection by Pascale Erhrenfreund), asteroidal bodies (see the article in this collection by Sandra Pizzarello) and icy bodies near the outer boundary of our solar system (Bernstein et al. 2002). Although organic molecules made in off-Earth locales almost certainly contributed to the reduced carbon inventory on Earth before life emerged, planetary processing on Earth undoubtedly also contributed to the inventory of prebiotic molecules that were available to life as it originated (assuming that Earth was the site of life's origin). Indeed, in the RNA first model for the origin of life on Earth (Joyce and Orgel 1999)(Benner

Editors: David Deamer and Jack W. Szostak

Additional Perspectives on The Origins of Life available at www.cshperspectives.org

Copyright (C) 2010 Cold Spring Harbor Laboratory Press; all rights reserved; doi: 10.1101/cshperspect.a003467

Cite this article as Cold Spring Harb Perspect Biol 2010;2:a003467 
S.A. Benner et al.

2009), it is often proposed that terran-based chemistry produced RNA in oligomeric form to initiate Darwinian evolution.

How are we to constrain models for planetary processing to converge on a model for what actually happened on Earth four billion years ago? Today, atmospheric dioxygen $\left(\mathrm{O}_{2}\right)$ readily converts organic materials to carbon dioxide, making it essentially impossible to observe such processing on the surface of Earth. Furthermore, the ubiquity of life on modern Earth means that any organic processing is more likely to reflect biology than prebiology. The closest we may come today to observe organic transformations absent biology on a planetary scale might be on Titan, a moon of Saturn whose atmosphere and surface is rich in reduced carbon.

Nevertheless, it is possible to apply a general understanding of organic chemical reactivity to suggest chemical reactions that might have occurred on early Earth and the products that they might have produced. These suggestions are constrained by models for the atmosphere and mineralogy of early Earth, although these constraints might change as models improve.

In this article, we assume that the atmosphere of early Earth was less oxidizing than today's atmosphere, although not as rich in methane as the simulated atmosphere used in the classic experiments of Stanley Miller (Miller 1955). Further, we assume that the atmosphere on early Earth had access to many sources of energy. These include electrical discharge, ultraviolet and visible light (although the Sun was almost certainly dimmer then than now, a Titan-like haze may have prevented high energy photons from reacting the Earth's surface), volcanism (providing not only heat but also reactive species and mixtures not at thermodynamic equilibrium), ionizing radiation, and impacts. (See Pizzarello and Shock 2010 for a discussion of such energy sources.)

We also assume that life emerged after the planet underwent a geological fractionation in which heavier minerals and elemental iron sank towards the core, leaving lighter rocks to form the crust. Open questions concern theinventory of water relative to the surface of early Earth, an inventory that determined whether planetary organic transformations might have occurred on dry land or below water on a planetary surface that was totally submerged.

\section{BACKGROUND}

Organic Molecules with Energy

Spontaneously Yield Polymers and Complex Mixtures

Any model for planetary organic chemistry must recognize that very few organic molecules are thermodynamically stable in water, either with respect to conversion to their fully hydrated state or decomposition upon heating to elemental carbon (charcoal), carbon dioxide, or other thermodynamic "end points." Accordingly, any model for planetary prebiotic chemistry must address the metastability of organic species. This word captures the concept that organic molecules that have appeared through the interaction of precursors with energy, water, and other organics can then disappear upon further interaction. As many authors have noted (Cairns-Smith 1982; Shapiro 1987; Shapiro 2007), any prebiotic reaction scheme that requires two or more organic species must be concerned about the metastability of two or more species; any scheme that does not produce both components in useful concentrations at the same time will not meet a standard of proof that the community need to accept a solution to the problem.

Here, too, the mineral inventory of early Earth cannot be ignored. Minerals of many kinds may have guided the reactivity of organic species that emerged on early Earth, altered their metastability, and influenced the time when specific organic species were available to emerging life.

\section{Carbohydrates Embody this Natural Propensity to Polymerize}

To explore these points and develop the scientific methods that enable this exploration, we will use carbohydrates as a focus. Carbohydrates are organic species having carbon, hydrogen and oxygen atoms in a ratio of 1:2:1. They are therefore at the same oxidation level of elemental carbon. Furthermore the simplest carbohydrate, 
formaldehyde ( $\mathrm{HCHO}, \mathrm{H}_{2} \mathrm{C}=\mathrm{O}$, or $\mathrm{C}_{1} \mathrm{H}_{2} \mathrm{O}_{1}$ ) is easily generated by electrical discharge or ultraviolet radiation impinging on moist atmospheres that are rich in carbon dioxide; nearly every contemporary model for early Earth permits such atmospheres (Pinto et al. 1980; Cleaves 2008). Because they contain ketone and aldehyde groups (see later), carbohydrates have interesting reactivity that includes the ability to form new carbon-carbon bonds under "standard conditions," defined as those where water is liquid under contemporary terran atmospheric pressure. By comparison, the compounds that often concern prebiotic chemists (carboxylic acids, fatty acids, and amino acids, for example) have essentially no such reactivity. Indeed, carbohydrates are "high energy" because they can rearrange their constituent atoms to give carboxylic acid derivatives and other more stable end point "sinks."

Recognizing this, some authors, most notably Arthur Weber (Weber 2001a; Weber 2001b; Weber 2007) (see Blackmond 2010), have exploited the reactivity, energy, and prebiotic accessibility of carbohydrates to suggest entire "carbohydrate world" metabolisms at or near life's origins. This exploits the energy of formaldehyde, hydroxyaldehydes and hydroxyketones relative to isomeric forms that have carboxylate groups, to do chemistry, much of it reminiscent of modern metabolism.

Unfortunately, others use the very same reactivity and energy to argue that carbohydrates could not have been present on early Earth (Shapiro 1988). For example, based on the short survival time of ribose, especially at high temperature and high $\mathrm{pH}$, Stanley Miller and his coworkers (Larralde et al. 1995) concluded that "ribose and other sugars were not components of the first genetic material" and precluded their presence in prebiotic scenarios. This is despite the fact that simple carbohydrates such as glycolaldehyde are well known in the cosmos (Hollis et al. 2000).

\section{ORGANIC CHEMISTRY SKILLS: A REMINDER}

This apparent paradox, where experts within the same community simultaneously exploit and preclude certain compound classes based on the same data, characterizes the "origins" field in general (Benner 2009). To evaluate such contradicting views, participants in this field must understand relevant features of bonding and reactivity in organic molecules. This understanding requires in turn that they understand the formalisms used by organic chemists to describe bonding and reactivity in organic molecules. Although the features and formalisms are taught in introductory organic chemistry courses, it is worth summarizing them here a prelude to discussing constraints on reactions that might be expected to occur in prebiotic environments.

First, a single bond joining two carbon atoms is strong, on the order of $400 \mathrm{~kJ}(\sim 100$ $\mathrm{kcal}$ ) per mole. This means that a pair of carbon atoms joined by a typical single bond will remain joined for many millions of years at temperatures when water is a liquid at sea level on Earth near neutral pH ("standard conditions"). This is also true for single bonds between carbon and hydrogen.

In contrast, single bonds between carbon and oxygen carbon and nitrogen, although similarly strong, but tend to be less persistent over time because they confer reactivity upon organic species that possess them. Heteroatoms (meaning neither carbon nor hydrogen) create centers of reactivity that are "weak" spots in organic compounds. In particular, they provide paths under standard conditions where bonds between carbon atoms or between carbon and hydrogen atoms can be broken at the same time as a bond to another atom is formed. This compensates the energy lost in the breaking bond with energy gained with a simultaneously forming bond, allowing the reaction to occur under relatively mild conditions.

Pairs of Electrons form Bonds between Atoms

Understanding ways that new bonds can form as old bonds are breaking is a key to understanding what reactions actually will occur under standard conditions. Recalling general chemistry, covalent bonds between two atoms are formed by the sharing of pairs of electrons (Fig. 1). Thus, in water $(\mathrm{H}-\mathrm{O}-\mathrm{H})$, the lines 
S.A. Benner et al.

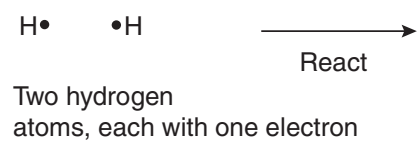

$H: \ddot{0}: H=H-\ddot{0}-H$

Water molecules are formed by the reaction of two hydrogen nuclei with an oxygen nuclei

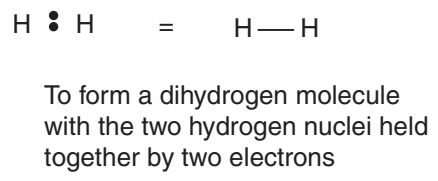

$\mathrm{H}: \mathrm{H}=\mathrm{H}-\mathrm{H}$

To form a dihydrogen molecule with the two hydrogen nuclei held together by two electrons

Figure 1. Lewis structures of chemical bonds for dihydrogen $\left(\mathrm{H}_{2}\right)$, water $\left(\mathrm{H}_{2} \mathrm{O}\right)$ and formaldehyde $\left(\mathrm{H}_{2} \mathrm{C}=\mathrm{O}\right.$, or $\mathrm{CH}_{2} \mathrm{O}$, or $\mathrm{HCHO}$ ).

between the hydrogen atoms and the central oxygen atom each represent a pair of electrons that form a single bond holding the two hydrogen atoms to the oxygen. In formaldehyde $\left(\mathrm{H}_{2} \mathrm{C}=\mathrm{O}\right)$, the double line between the carbon and the oxygen represents two pairs of electrons; four electrons in total bind the $\mathrm{C}$ atom to the $\mathrm{O}$ atom.

Chemists frequently do not write symbols representing all of the atoms and electrons. Therefore, the first skill required in analyzing reactivity in organic chemistry requires that one put back into a structure the symbols that practiced chemists do not write (but understand are there), completing the structure of the organic molecule. This ensures that the analysis reflects all of the atoms and electrons in a molecule.

A structure completed in this way is known as a Lewis structure. A Lewis structure explicitly indicates electrons that are not involved in bonding. For example, in the Lewis structure of water, oxygen carries two pairs of unshared electrons from the outer valence shell. We represent each of these valence electrons not involved in a bond by a dot. Hence, the oxygen in the $\mathrm{H}-\mathrm{O}-\mathrm{H}$ structure has four dots, representing electrons on the oxygen but not involved in bonding. Likewise, the oxygen in formaldehyde carries two pairs of unshared electrons, represented again by four dots on the oxygen in the Lewis structure.

\section{A Nucleophilic Center Brings a Pair of Electrons to Form a New Bond}

As a chemical bond is a pair of electrons between two atoms, any unshared pair of electrons is available in principle to form a new bond. Further, if a bond breaks, the electrons that were in that bond are available to form a new bond. Atoms that contain pairs of electrons available to form a new bond (or can get them by breaking a bond) are called nucleophilic centers (Fig. 2).

To form a bond, the electron pair from the nucleophilic center must find an atom that has a vacant orbital or can get one by losing a bond through breakage. This atom is called an electrophilic center. An archetypal electrophile is a proton $\left(\mathrm{H}^{+}\right)$. A proton is not bonded to anything, has a vacant $1 s$ bonding orbital, so it can form a bond with a single partner (Fig. 3). An archetypal nucleophilic center is the oxygen atom on water. It carries an unshared pair of electrons that can form a new bond to $\mathrm{H}^{+}$. The product of the reaction between water and $\mathrm{H}^{+}$is $\mathrm{H}_{3} \mathrm{O}^{+}$(the hydronium ion).

\section{Curved Arrows Describe the Movement of Pairs of Electrons}

Organic chemists use curved arrows to describe reactions between nucleophilic and electrophilic centers that produce a new bond. The curved arrow begins with an unshared pair of 
Planetary Organic Chemistry and the Origins of Biomolecules
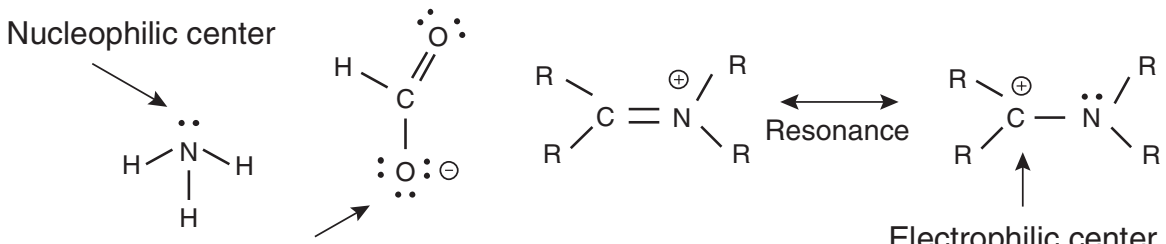

Nucleophilic center

Electrophilic center

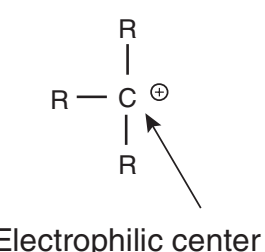<smiles>CC(C)=O</smiles>

$\mathrm{H}$<smiles></smiles>

Electrophilic center

Figure 2. Nucleophilic centers have an unshared pair of electrons that can form a new bond, or can get one (via resonance, for example). Electrophilic centers have a vacant orbital (or can get one via resonance, for example) that can accept an unshared pair of electrons from a nucleophilic center to form a new bond. In a resonance form a pair of electrons moves between adjacent atoms (electrons are dynamic entities), creating a new representation for the same molecule. The resulting resonance forms are joined by a double headed arrow to indicate equivalence.

electrons on the nucleophile, the pair that will form the new bond in the product. The arrow is drawn to end at a position (on the structures of the reactants) where the electron pair will be after the bond is formed. Figure 3 shows the reaction of the unshared pair of electrons on the oxygen of water (the nucleophilic center) with $\mathrm{H}^{+}$(the electrophilic center) to give $\mathrm{H}_{3} \mathrm{O}^{+}$.

When nucleophilic centers bear an electron pair prominently placed in a correctly drawn Lewis structure, they are easy to spot. They are

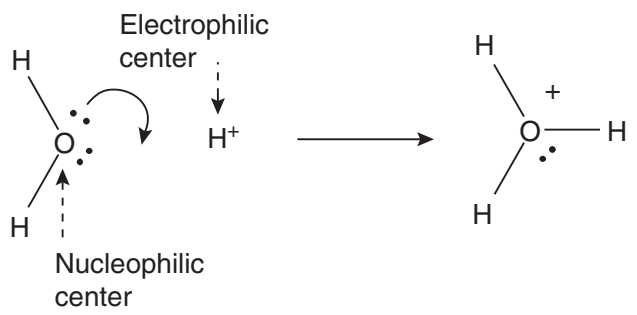

Figure 3. Reaction of the nucleophilic center on the oxygen of water with an electrophilic center, $\mathrm{H}^{+}$. The movement of a pair of electrons in the reaction is illustrated using a curved arrow. The result is $\mathrm{H}_{3} \mathrm{O}^{+}$, the hydronium ion. less easy to spot when they get the electron pair needed to form a future bond by breaking an existing bond. The same is true for electrophilic centers that obtain vacant orbitals available for forming new bonds only after an existing bond is broken.

For example, the carbon of formaldehyde $\left(\mathrm{H}_{2} \mathrm{C}=\mathrm{O}\right)$ has all of its four valences occupied. That carbon does not seem to have a valence available to form a new bond with anything. If, however, one of the two bonds between carbon and oxygen breaks, with the electron pair moving from a position between the carbon and the oxygen to a new position on the oxygen, then the carbon center has a valence free and can undergo nucleophilic attack by an oxygen atom, for instance, from a nearby $\mathrm{H}_{2} \mathrm{O}$ molecule.

This process is shown using curved arrows in Figure 4. Here, a bond between carbon and oxygen is broken at the same time as the carbon forms a new bond to an incoming oxygen atom. At the same time as the energy in the second $\mathrm{C}-\mathrm{O}$ bond is lost through breakage, the energy of a new $\mathrm{C}-\mathrm{O}$ bond is gained. The resulting product is the hydrate of formaldehyde $\left(\mathrm{H}_{4} \mathrm{CO}_{2}\right)$. 
S.A. Benner et al.

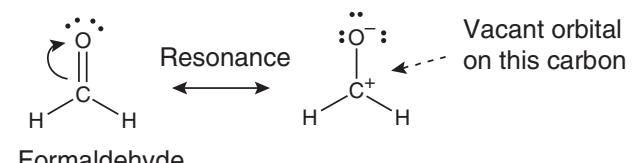

Formaldehyde

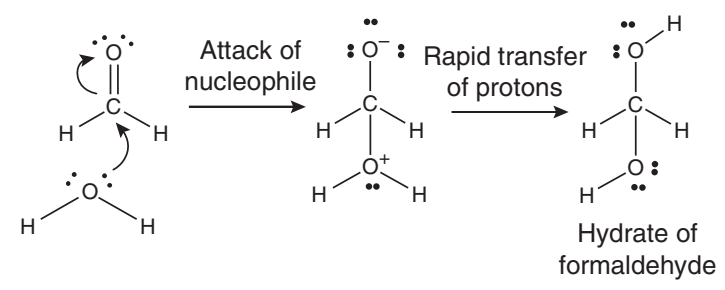

Figure 4. Reaction of the nucleophilic center on the oxygen of water with an electrophilic center, the carbon atom of formaldehyde forms the hydrate of formaldehyde. The movement of a pair of electrons in the reaction is illustrated using a curved arrow.

\section{CURVED ARROW MECHANISMS FOR THE PREBIOTIC SYNTHESIS OF BIOLOGICAL MOLECULES}

The curved arrow tool can be used to describe most reactions of organic molecules under standard conditions. This includes transformations that might have converted formaldehyde in a prebiotic world into molecules that are characteristic of contemporary terran life.

\section{Curved Arrow Mechanisms for the Formation of Amino Acids}

The curved arrow formalism can be used to describe the synthesis from formaldehyde, ammonia, cyanide and water of a simple amino acid, glycine $\left(\mathrm{NH}_{2} \mathrm{CH}_{2} \mathrm{COOH}\right)$, one of the basic building blocks of proteins. The steps are shown in Figure 5 with species both named and numbered for future reference.

Ammonia (2) has three hydrogen atoms and one nitrogen atom. A Lewis structure shows that the nitrogen in ammonia also carries an unshared pair of electrons. The nitrogen atom is therefore a nucleophilic center. Ammonia should therefore react with formaldehyde (1) for the same reason that water does. In this reaction, the unshared pair of electrons on ammonia forms a new bond between its nitrogen and the carbon of formaldehyde, just as the pair of electrons forming the second carbon-oxygen bond leaves to form a new bond between the oxygen and $\mathrm{H}^{+}$. This generates an "amino alcohol" (3).
After the transfer of some of the hydrogen atoms, the nitrogen of the amino alcohol again has an unshared pair of electrons, and is able to form a second bond with the carbon atom. The resulting compound is known as an imine (4), which contains a $\mathrm{C}=\mathrm{N}$ unit having a carbon atom bonded twice to a nitrogen atom.

The carbon of the $\mathrm{C}=\mathrm{N}$ unit is also an electrophilic center. This sets the stage for the next reaction, where the carbon of the cyanide anion (5) attacks the imine (4) carbon to form an aminonitrile (6). The nitrile has a $\mathrm{C} \equiv \mathrm{N}$ unit, where the nitrogen is bonded three times to the carbon. This carbon is again an electrophilic center. If a pair of electrons forming one of the bonds between carbon and nitrogen leaves to form a bond with $\mathrm{H}^{+}$, then the carbon has a free valence. It is therefore available to form a bond with a nucleophilic oxygen atom from water.

The product, again after $\mathrm{H}^{+}$atoms are transferred, has another $\mathrm{C}=\mathrm{O}$ group in a unit known as an amide (7). The carbon atom of the amide is again an electrophilic center; it can be attacked by the nucleophilic oxygen of another water molecule. This leads to the hydrolysis (taking on a water molecule) of the amide and the formation of the amino acid glycine, together with an ammonia molecule.

The net process is the reaction of one molecule of formaldehyde, one molecule of hydrogen cyanide, and one molecule of water to give one molecule of glycine $(\mathbf{8})$. In terms of 
Planetary Organic Chemistry and the Origins of Biomolecules
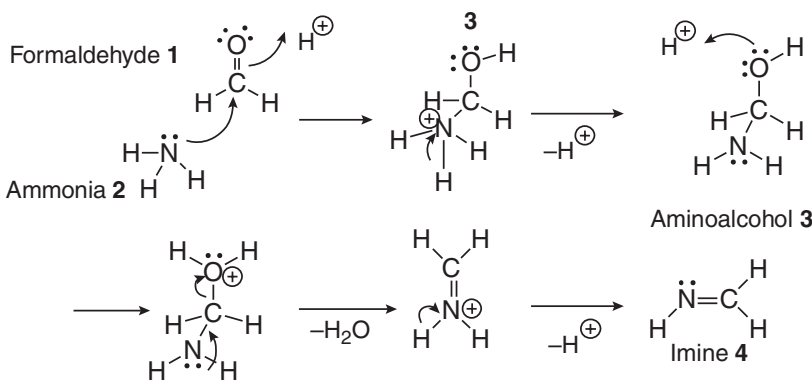

Aminoalcohol 3
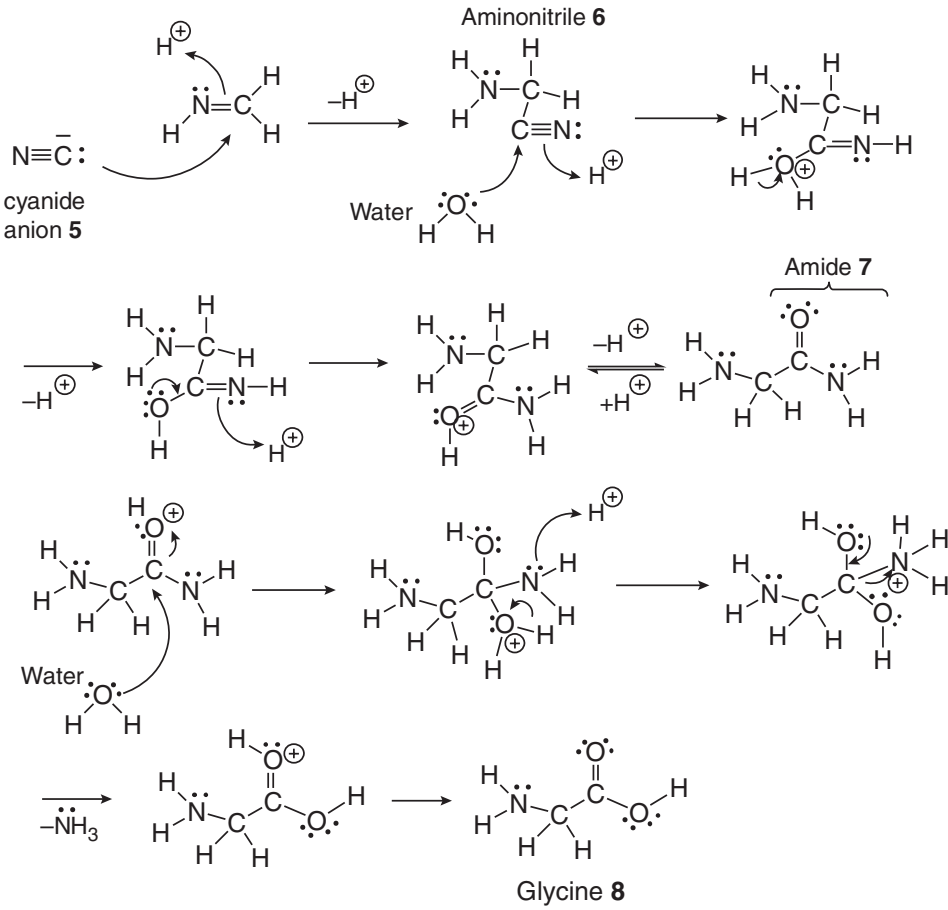

Figure 5. The Strecker synthesis of glycine, an amino acid. Reaction of the nucleophilic centers on the nitrogen of ammonia, the carbon of the cyanide anion and the oxygen of water with electrophilic centers on formaldehyde and key intermediates. The movements of pairs of electrons in the reactions are illustrated using curved arrows.

chemical formulas, the reaction is $\mathrm{HCHO}+$ $\mathrm{HCN}+\mathrm{H}_{2} \mathrm{O}=\mathrm{C}_{2} \mathrm{H}_{5} \mathrm{NO}_{2}$; this equation "balances." Ammonia is used in the first step, and is released in the last step. Therefore, ammonia is a catalyst for the reaction, being consumed and formed in equal amounts in the reaction cycle.

This sequence of reactions is known as the Strecker synthesis of amino acids, named after the chemist who developed it in the 1860s. The Strecker synthesis is driven by the innate reactivity of nucleophiles and electrophiles, and proceeds spontaneously and in reasonable yield. Further, the Strecker synthesis is quite general. It can be used to prepare any amino acid for which the corresponding aldehyde is available, not just formaldehyde. For example, if we start with acetaldehyde $\left(\mathrm{CH}_{3} \mathrm{CHO}\right)$ rather than formaldehyde, the amino acid alanine $\left(\mathrm{CH}_{3} \mathrm{CH}\left(\mathrm{NH}_{2}\right) \mathrm{COOH}\right.$ ) is formed (Fig. 6). Analogous processes can be drawn for many of the amino acids found commonly in proteins from terran organisms.

The Strecker pathway accounts for some products found in Stanley Miller's experiments attempting to reproduce early Earth's atmosphere (Miller 1955). Miller found that amino 
S.A. Benner et al.

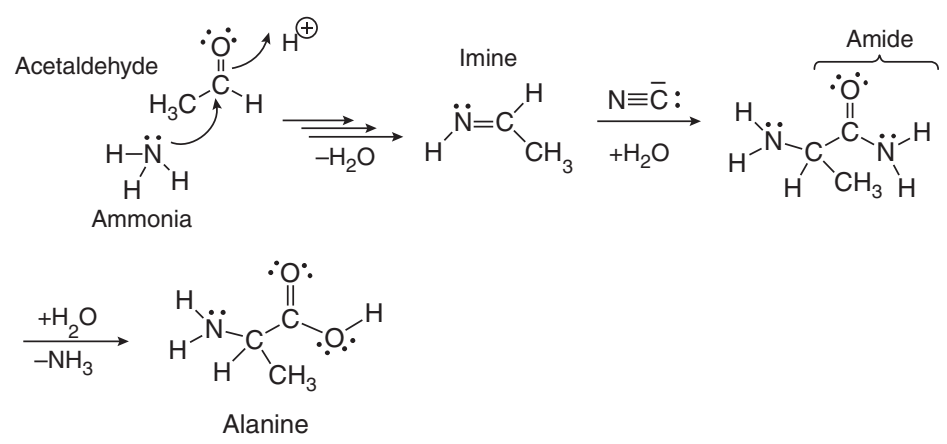

Figure 6. Strecker synthesis of alanine starting from acetaldehyde.

acids were generated after electrical discharges from electrodes were passed through an atmosphere of hydrogen, methane, and ammonia over water. The electrical discharge appears to have generated the formaldehyde and cyanide needed as precursors for Strecker syntheses. Once these were formed, the synthesis of amino acids occurred spontaneously.

The simulated atmosphere chosen by Miller for his laboratory experiments was considered at the time to approximate the atmosphere of early Earth. Today, many models hold that the amount of methane on early Earth was much smaller than that used in the Miller experiments. Instead, the carbon inventory of the early Earth is today modeled as being present largely as carbon dioxide (Kasting 1993).

Accordingly, nonbiological syntheses of biomolecules under these conditions have been sought. Again, organic molecules are easy to get when carbon dioxide and water is subjected to electrical discharge, ionizing radiation, and ultraviolet light. The results obtained under a variety of conditions are complex red-brown mixtures of organic molecules, often called "tholins" (without making a distinction between what those mixtures contain) (Sagan et al. 1978) (Sagan and Khare 1979). A partial inventory of molecules comprising certain tholins is shown in Table 1. As the atmosphere of Titan is also red-brown complex mixture of organics, it too may be said to contain "tholins," although by ignoring the details of the mixture, this name is not particularly useful. However, there is little doubt that both formaldehyde and hydrogen cyanide are key intermediates being generated from these atmospheres as well.

\section{Curved Arrow Mechanisms for Forming Nucleobases for RNA and DNA}

Curved arrow mechanisms can be used to generate nonbiological routes for the synthesis of many molecules in biology. For example, the

Table 1. Some organic compounds identified in tholin mixtures. (Sagan et al., 1978; Sagan \& Khare, 1979; Pietrogrande et al., 2001).

\begin{tabular}{lll}
\hline Hydrogen sulfide & Hexene & Formamide* $^{*}$ \\
Hydrogen cyanide & Heptene & Pyridine* $^{*}$ \\
Ammonia & Butadiene & Styrene* $^{*}$ \\
Ethane & Benzene & 2,3 Pentadiene* \\
Propane & Toluene & 2-Methylpyrimidine* \\
Butane & Thiophene & -Methylpyrmidine \\
Ethene & 2-Methyltiophene & 3- Butenenitrile* \\
Propene & Methylmercaptan & Butyne* \\
Butene & Ethylmercaptan & Acetonitrile* $^{*}$ \\
Pentene & Propylmercaptan & Carbon dioxide* $^{*}$ \\
Carbon disulfide & Methylisocyanate & Acetamide* $^{*}$ \\
\hline
\end{tabular}


Planetary Organic Chemistry and the Origins of Biomolecules

Oró-Orgel synthesis (Fig. 7) exploits the reactivity of $\mathrm{HCN}$ to make adenine $\left(\mathrm{C}_{5} \mathrm{H}_{5} \mathrm{~N}_{5}\right)$, one of the five nucleobases (symbolized as A, C, T, G, and $\mathrm{U}$ ) used to store information in DNA and RNA. The cyanide anion again reacts as a nucleophile, this time with a molecule of $\mathrm{HCN}$ serving as an electrophile. The combination of reactions was studied in the laboratory Sanchez, Ferris, and Orgel, and provides one of the canonical examples of nucleophile-electrophile chemistry (supplemented with some photochemistry) in the prebiotic chemistry literature (Oró 1960; Sanchez et al. 1967).

\section{Curved Arrow Mechanisms for Forming Carbohydrates}

Amino acids are "easy" components of modern terran biochemistry from the perspective of metastability. The carboxyl group of an amino acid has a $\mathrm{C}=\mathrm{O}$ unit. Although this carbon is potentially an electrophilic center just as the $\mathrm{C}=\mathrm{O}$ unit of formaldehyde is, the $\mathrm{C}=\mathrm{O}$ unit of a carboxylic acid is also attached to an $-\mathrm{OH}$ unit. This, at neutral $\mathrm{pH}$, loses an $\mathrm{H}^{+}$and becomes a $\mathrm{COO}^{-}$carboxylate anion, a species having a negative charge. This negative charge discourages any electron rich nucleophile from attacking the $\mathrm{C}=\mathrm{O}$ unit of a carboxylic acid, making it rather stable under standard conditions. The other bonds in an amino acid are single bonds, including $\mathrm{C}-\mathrm{C}, \mathrm{C}-\mathrm{H}$, and $\mathrm{C}-\mathrm{N}$ bonds. These are, as noted earlier, also rather stable. This means that amino acids are quite metastable, a feature of their reactivity that undoubtedly accounts for their presence in meteorites.

Metastability is a more serious issue with respect to carbohydrates. Many reaction schemes might give carbohydrates under prebiotic conditions. However, carbohydrates are often unstable under the conditions where they are formed. Let us review just two examples where synthesis of carbohydrates is possible, at least the laboratory, before turning to metastability as an issue.

For example, Eschenmoser exploited the reactivity $\mathrm{C}=\mathrm{O}$ aldehyde groups to generate ribose, the carbohydrate found in RNA. His

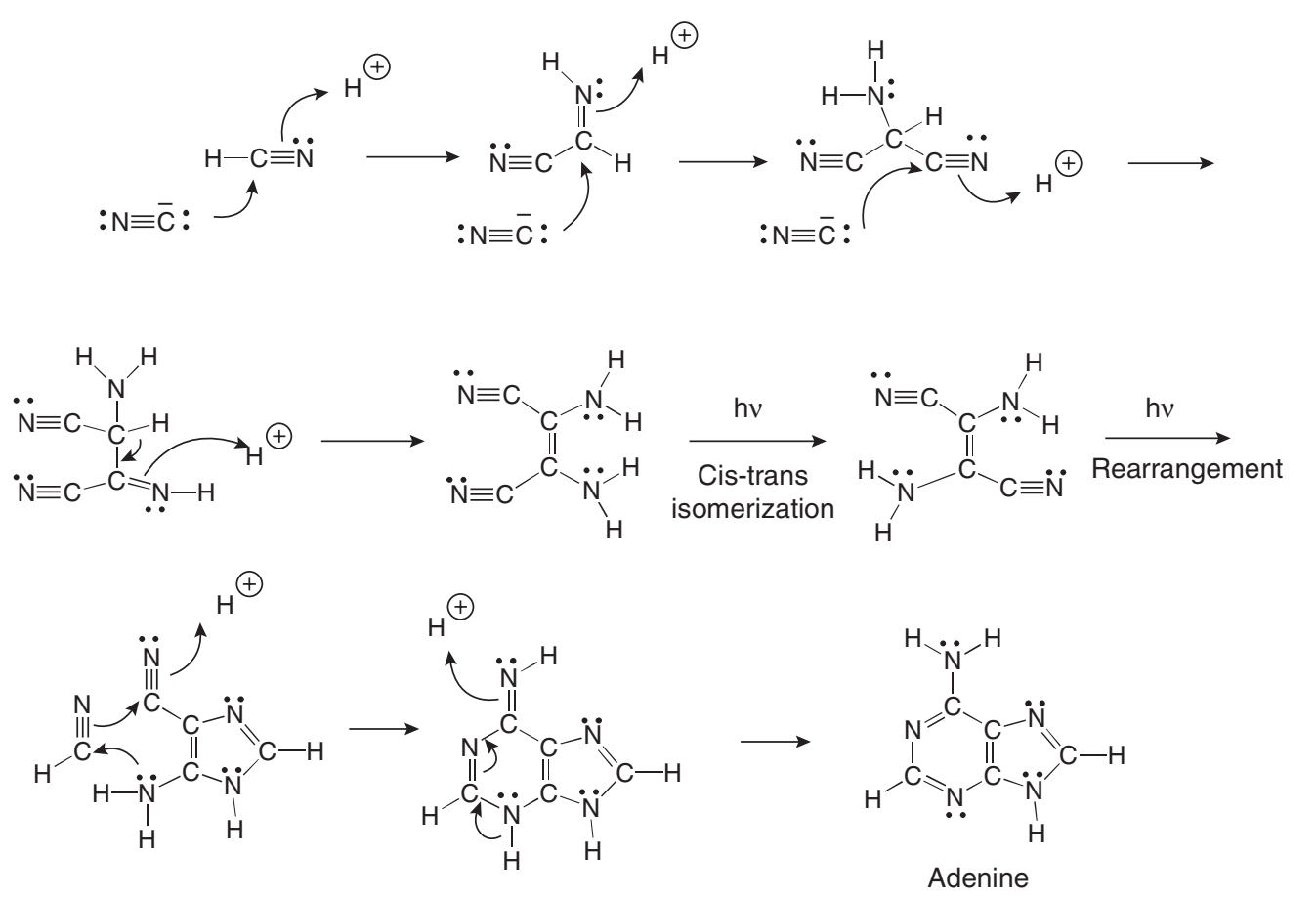

Figure 7. HCN yields adenine via the Oró-Orgel synthesis. 
S.A. Benner et al.

proposed reaction sequence begins with an interesting starting material derived from $\mathrm{HCN}$ having two C-N single bonds in a three-membered ring (Fig. 8). Key in this process is the use of phosphate as a nucleophile to break one of these C-N single bonds, replacing a C-N bond by a $\mathrm{C}-\mathrm{O}$ bond. The breakability of the $\mathrm{C}-\mathrm{N}$ bond is enhanced because it is strained in a threemembered ring.

The resulting intermediate is called a cyanohydrin. It can fall apart to give an imine (a structure with a $\mathrm{C}=\mathrm{N}$ unit that we saw in the Strecker synthesis). The imine can be hydrolyzed by water to forms an aldehyde having an -Ophosphate unit next to the $\mathrm{C}=\mathrm{O}$ unit; this is called glycolaldehyde phosphate. This species can enolize and add formaldehyde to give glyceraldehyde (we will discuss enolization and addition reactions more in a bit), which can serve as an electrophile to form a new bond to the enol of a second glycolaldehyde, to give ribose-2,4-diphosphate as a major product.
Not quite ribose, but a very interesting product nevertheless. This process occurs in the laboratory when the starting materials are mixed with formaldehyde (Mueller et al. 1990). The starting material has not been detected naturally in the cosmos by microwave spectroscopy, but this is hardly dispositive; the material would be difficult to detect.

Another route for the prebiotic synthesis of carbohydrates is based on the formose process, described more than a century ago by the Russian chemist Aleksandr Butlerov (Butlerov 1861). If one incubates formaldehyde ( $\mathrm{HCHO})$ in a hot solution of calcium hydroxide $\left(\mathrm{Ca}(\mathrm{OH})_{2}, \mathrm{pH} 12.5\right)$, nothing happens at first. However, after some time, the formaldehyde is rapidly consumed. The mixture turns brown and acquires a sweet taste; the product formose smells like toasted marshmallows. Further, if the reaction is stopped at the right time, some five-carbon carbohydrates can be isolated from it, perhaps even ribose.

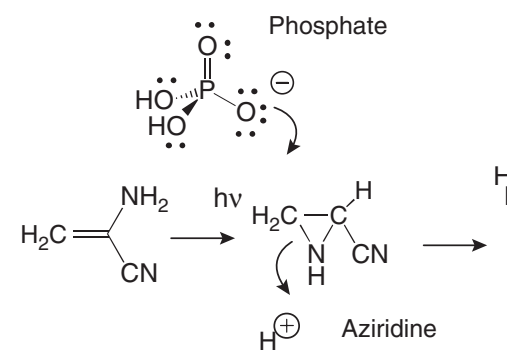
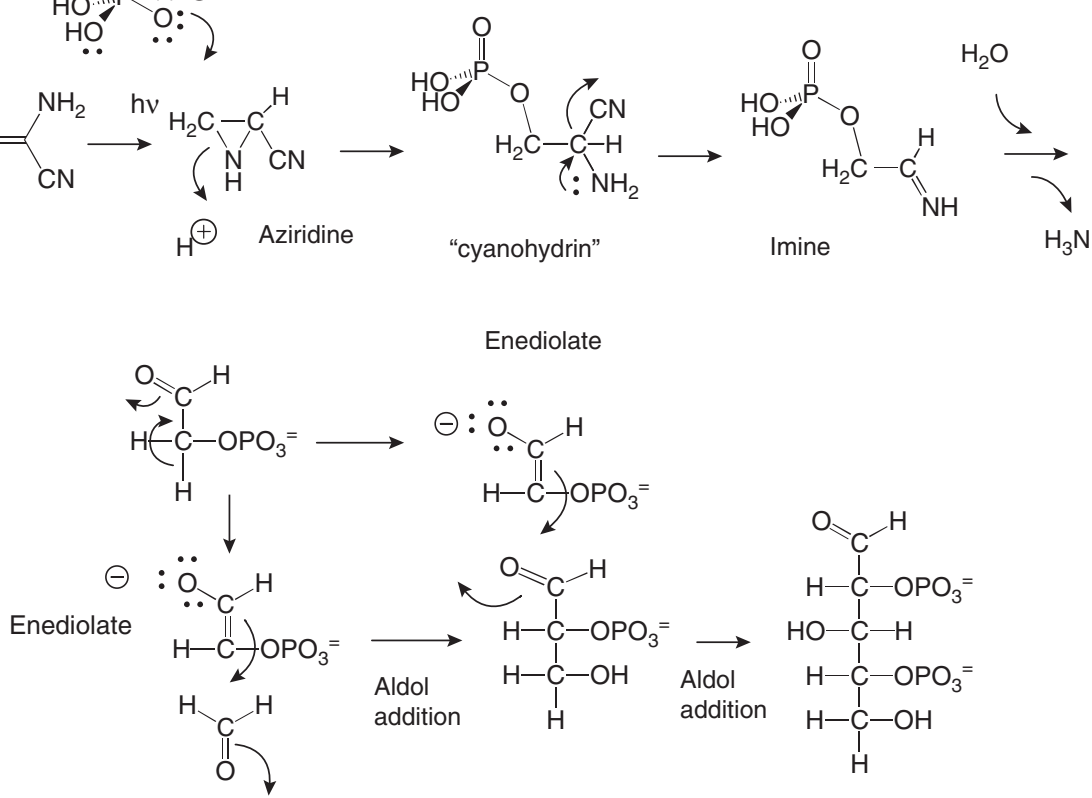

Figure 8. The Eschenmoser synthesis of ribose-2,4-diphosphate from a proposed starting material derived from $\mathrm{HCN}$. 
A half century ago, modern chemical analysis was brought to bear on the process by Ronald Breslow (Breslow 1959). It involves the repetition of two reactions shown in Figure 9:

1. removal of a proton $\left(\mathrm{H}^{+}\right)$from a carbon next to a $\mathrm{C}=\mathrm{O}$ (carbonyl) group, known as enolization, and

2. attack of the resulting enediolate (a nucleophile) on $\mathrm{HCHO}$ (an electrophile) to form a new carbon-carbon bond, known as an aldol addition.

By repeating these reactions again and again, complex mixtures of organic species, all having a ratio of carbon:hydrogen:oxygen of 1:2:1 (just like the starting formaldehyde) can be generated. A subset of these reactions is shown in Figure 10.

Many popular books on the origin of life regard the formose process as a solution to the problem of prebiotic carbohydrate formation (Dyson 1985); some see it as a satisfactory approach for the prebiotic synthesis of ribose. This is not the current consensus, however (Shapiro 2007). Both the complexity of the product mixture (as shown in Fig. 10) and the metastability of its components are at issue. Many of those components themselves have $\mathrm{C}=\mathrm{O}$ units (and therefore can react as electrophiles). Many of these compounds also have a C-H unit adjacent to the $\mathrm{C}=\mathrm{O}$ unit. From these, $\mathrm{H}^{+}$can be lost in an enolization reaction, allowing them to react further as nucleophiles. Eventually, the products in the mixture undergo still more reactions that are too many to capture in a single figure (and this is before considering chirality). Unfortunately, five carbon carbohydrates such as ribose, of particular interest for the RNA-first model for the origin of life, are also metastable. They react further, especially at high $\mathrm{pH}$.

\section{SOLVING THE METASTABILITY PROBLEM IN CARBOHYDRATE CHEMISTRY}

\section{Appendages to Carbohydrates to Improve} their Metastability

Two general classes of solution have been proposed to address the complexity and metastability of carbohydrate formed by prebiotic processes. One proposes that free carbohydrates were never formed on early Earth as prebiotically relevant species. In this class of solution, carbohydrates are proposed to have entered early metabolism joined to another chemical moiety that improves their stability. One proposal is described by John Sutherland, who appends the emerging carbohydrate to an emerging nucleobase (Powner et al. 2009).

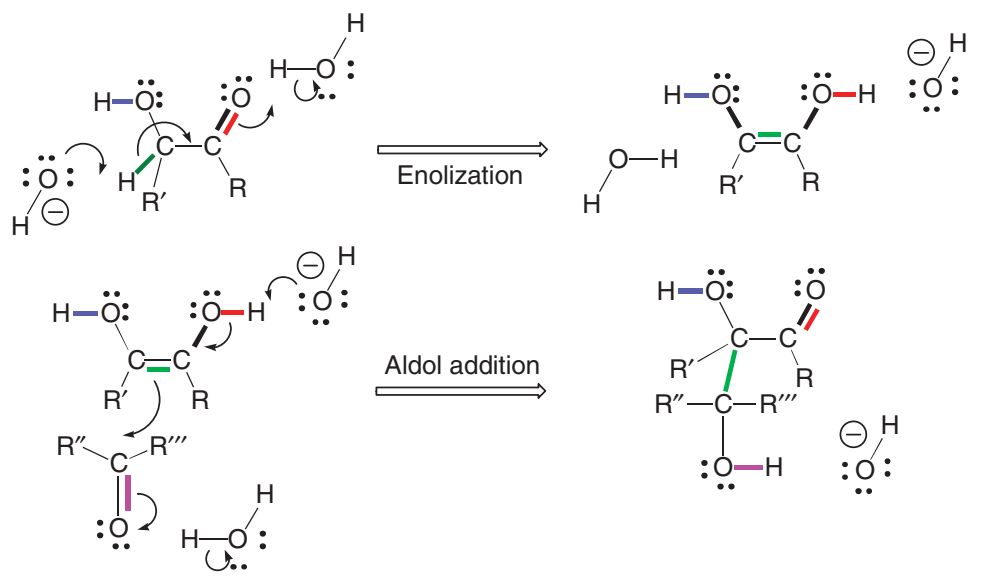

Figure 9. Two reaction types create formose. Top. In an enolization reaction, a base (here, hydroxide) removes a proton $(\mathrm{H}+)$ from a carbon adjacent to a $\mathrm{C}=\mathrm{O}$ unit to give an enediol. The enediol can then react as a nucleophile in an aldol addition reaction. Bottom. In an aldol addition reaction, an enediol reacts as a nucleophile to form a new bond to the $\mathrm{C}$ of a $\mathrm{C}=\mathrm{O}$ unit (the electrophilic center). If the carbonyl species is formaldehyde, $\mathrm{R}^{\prime \prime}=\mathrm{R} "=\mathrm{H}$. 

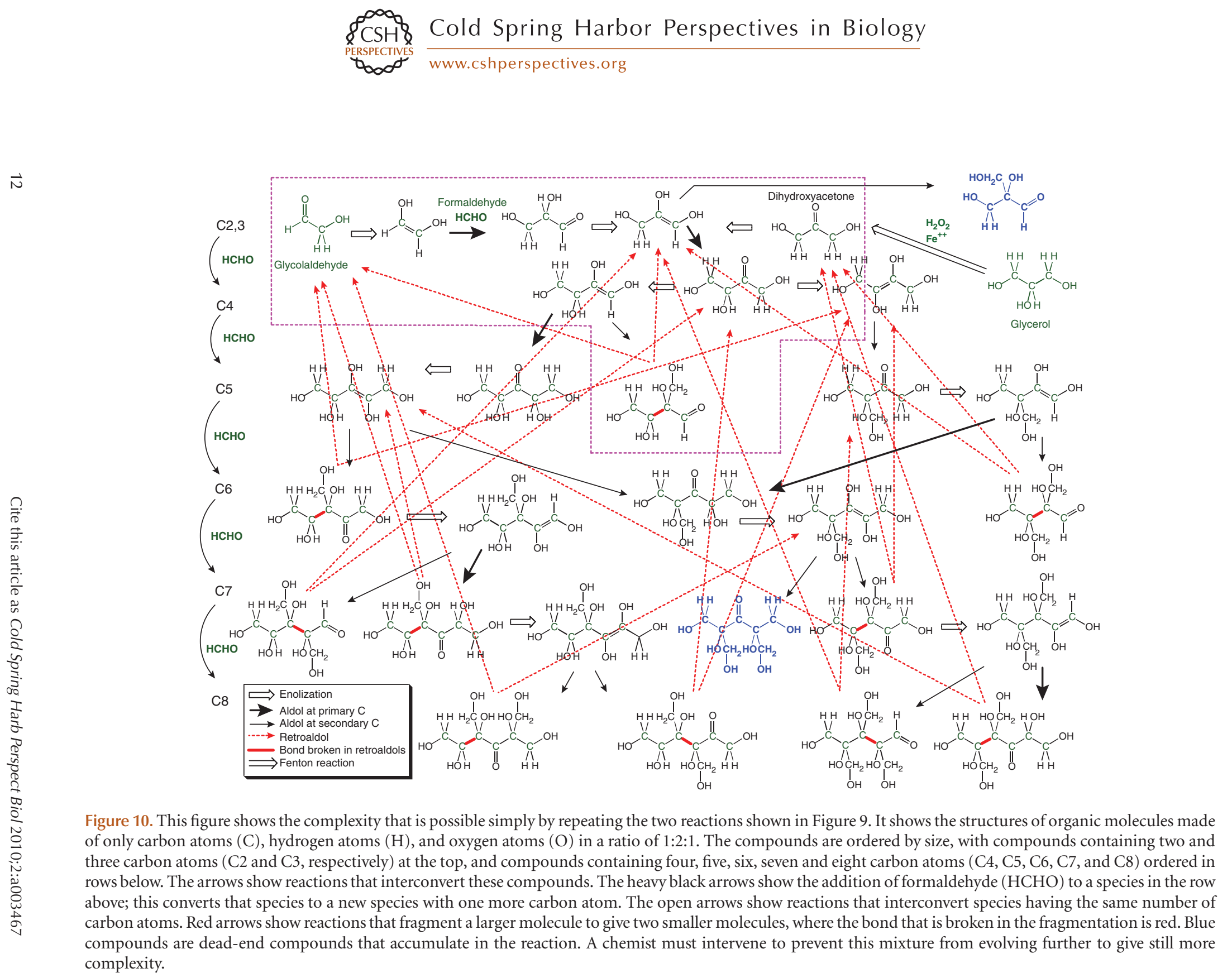
Eschenmoser's proposal (Fig. 8) embodies a similar idea. By introducing phosphate early in the sequence, the intermediates are not glycolaldehyde, glyceraldehyde, and ribose, but rather glycolaldehyde phosphate, glyceraldehyde phosphate, and ribose-2,4-diphosphate. The negative charges on the phosphate groups diminish the rate at which $\mathrm{H}^{+}$is removed, therefore decreasing the rate of enolization. The phosphates attached to these carbohydrates therefore decreases the reactivity of these species as nucleophiles, allowing them to survive longer under conditions where they are formed.

It remains to be seen whether attaching carbohydrate fragments to these or other groups increases metastability sufficiently to allow the carbohydrate derivatives to be plausible prebiotic participants in subsequent reactions proposed in an RNA-first model for the origin of life. It is clear, however, that the universe of chemical structures is far from explored for possible attachments that might confer metastability with respect to decomposition and (still better) activation for the next steps in a useful prebiotic sequence that does not require continued human intervention. Much more work in this direction is needed.

\section{Minerals to Improve the Metastability of Carbohydrates}

A second line of thinking looks to the mineral world to preserve carbohydrates long enough to allow them to accumulate to an extent useful for them to participate in subsequent steps in a prebiotic synthesis of Darwinian chemical systems (Prieur 2001; Ricardo et al. 2004). The role of mineral elements to create new reactivity has been reviewed by Robert Hazen. Here, we consider the opposite, the use of mineral elements to remove reactivity.

Several elements in mineral form are known to bind to carbohydrates in a way that diminishes their reactivity. The best known of these are borate (Chapelle and Verchere 1988), silicate (Lambert et al. 2004), vanadate, molybdate, germanate, and (to a lesser extent) aluminate (Schilde et al. 1994). Purely formally, these are derived from the acids $\mathrm{H}_{3} \mathrm{BO}_{3}, \mathrm{H}_{4} \mathrm{SiO}_{4}, \mathrm{HVO}_{3}$,
$\mathrm{H}_{2} \mathrm{MoO}_{4}, \mathrm{H}_{4} \mathrm{GeO}_{4}$, and $\mathrm{H}_{3} \mathrm{AlO}_{3}$, although many of these acids are not observed, preferring to precipitate or form complex ions. Silicic acid, for example, precipitates as $\mathrm{SiO}_{2}$, the mineral known as quartz, in many forms, including gem opal.

Consider, for example, boron. Standing right before carbon in the Periodic Table, boron has only three electrons in its outer shell. This means that boron must pick up five more electrons to get the eight that it wants in its outer shell.

Oxygen atoms in water or the -OH hydroxyl groups of organic molecules offer those electrons. Each of these oxygens has two unshared pairs of electrons. Therefore, boron (III) atoms bind to water oxygens. In geology, borate is an anion whose central boron atom is bonded to four oxygen atoms.

Boron bonds especially well to organic molecules that have two adjacent hydroxyl groups, molecules known as 1,2-diols. Pentoses like ribose in their cyclic forms (Fig. 11) are 1,2-diols. Their adjacent -OH groups bind borate tightly (Fig. 12). Still better, their cyclic borate complexes lack $\mathrm{C}=\mathrm{O}$ groups necessary for carbohydrates to react to form tar.

As many have noted, the borate complex of ribose is stable, even at high $\mathrm{pH}$. Indeed, for over 40 years, this stability has been used as part of synthetic procedures in the laboratory that interconvert ribose and other five-carbon sugars, including ribulose and arabinose (Angyal 2001; Mendicino 1960).

To convert this common knowledge into a useful prebiotic hypothesis, two questions are relevant. The first asks whether minerals containing borate are likely to be available on prebiotic Earth. As an element, boron is scarce in the cosmos (Zhai and Shaw 1994), especially relative to silicon, carbon, and other familiar elements. Balancing this is the fact that boron is not a good mineral-forming species. It therefore tends to be concentrated in residual igneous melts, where it appears on the surface. The predominant mineral species containing boron are tourmalines. These are easily weathered in acid to form borate salts, which are quite water-soluble.

The fate of water-soluble borate salts depends on whether run-off streams deliver 
S.A. Benner et al.
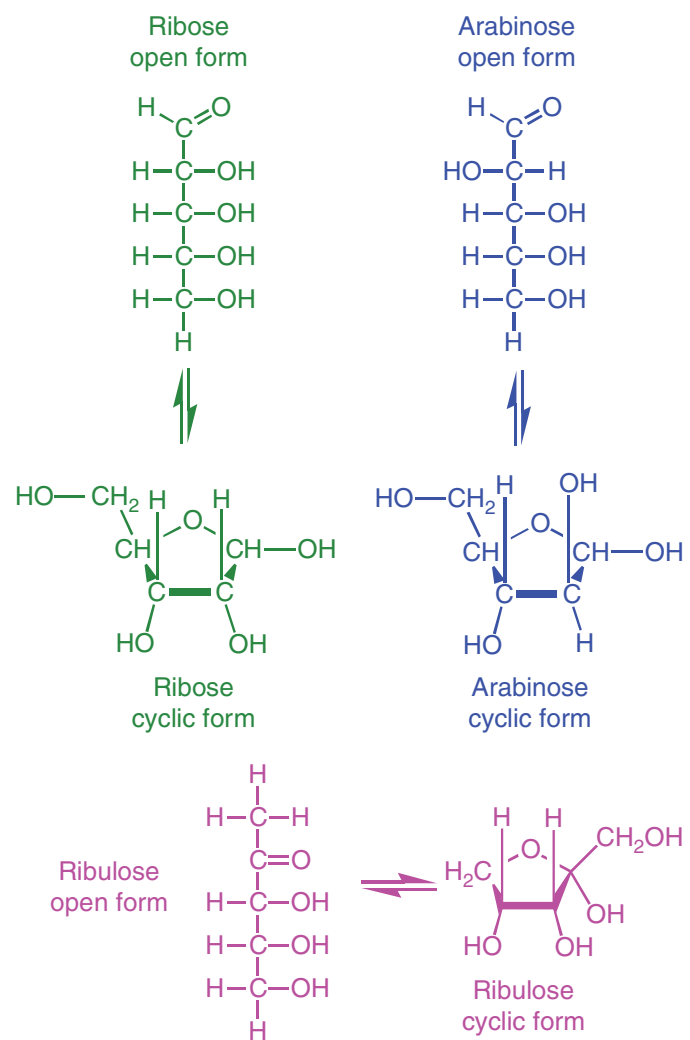
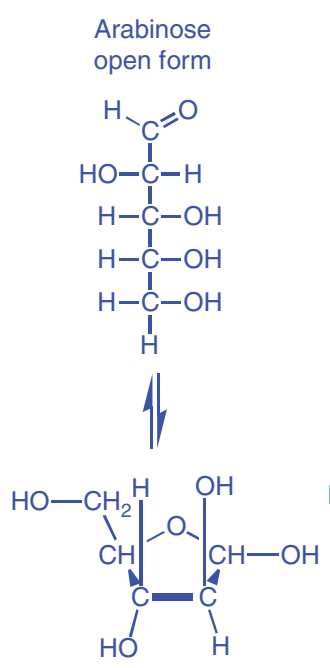

Arabinose

Arabinose
cyclic form

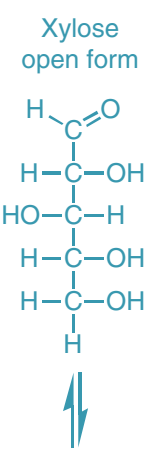

$\mathrm{OH}$

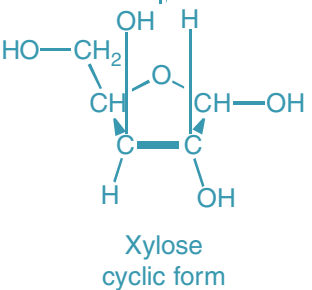

cyclic form
Lyxose

open form

$\mathrm{H}_{-\mathrm{C}}=\mathrm{O}$

$\mathrm{HO}-\mathrm{I}-\mathrm{C}$

$\mathrm{HO}-\mathrm{l}-\mathrm{H}$

$\mathrm{H}-\mathrm{I}-\mathrm{OH}$

$\mathrm{H}-\mathrm{C}-\mathrm{OH}$

11<smiles>OC[C@@H]1C2CC(CO)(O2)C(O)C1O</smiles>

Lyxose

cyclic form

Figure 11. Carbohydrates with 5 carbons (pentoses or pentuloses, penta=5). Pentoses have a $\mathrm{HC}=\mathrm{O}$ group in their open form; pentuloses have a $\mathrm{C}=\mathrm{O}$ unit flanked by two carbons All have the formula $\mathrm{C}_{5} \mathrm{H}_{10} \mathrm{O}_{5}$. All can exist in both open and cyclic forms, as the $\mathrm{C}$ of the $\mathrm{C}=\mathrm{O}$ unit is an electrophile and can react with the $\mathrm{O}$ of an $-\mathrm{OH}$ group as a nucleophile to form a ring. In many cases, more than one cyclic form is possible. Different pentoses differ in how their atoms are arranged in space. We represent these 3D orientations on a 2D sheet of paper by drawing thicker bonds (which are forwards) and placing the $\mathrm{H}$ and $\mathrm{OH}$ groups up or down. Cyclic pyranose forms (with six atoms in the ring) are not shown.

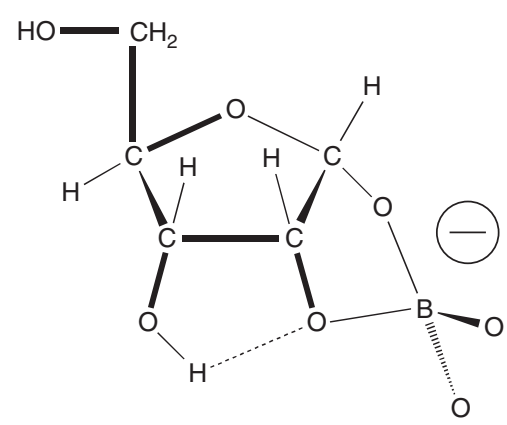

Figure 12. The NMR structure of the borate-ribose complex, with boron complexing adjacent 1,2hydroxyl groups. them. If they run into the ocean, borate is diluted. However, if they end up in a dry basin such as Death Valley or the Dead Sea, borates end up in minerals evaporated from water (evaporites). Borax, a sodium borate salt, is one of these minerals, and is mined in Death Valley. Other boron minerals found in Death Valley include ulexite, a sodium calcium borate mineral, and colemanite, which is a calcium borate.

Alkali is also easily generated from igneous rocks. One source for alkalinity in geology is the mineral peridotite (its gem form is peridot). This green mineral is a magnesium iron silicate, and is widespread in rocks called serpentines. When serpentines erode in water, serpentinization occurs. Serpentinization is a process 
Planetary Organic Chemistry and the Origins of Biomolecules

that creates dihydrogen gas, the related reducing power, reduced organic molecules, and magnesium hydroxide, a base. For example, Lake Mono, just to the east of the Sierra Nevada mountains in California, has a $\mathrm{pH}$ as high as 12 , similar to the $\mathrm{pH}$ in the laboratory formose reaction, all arising via serpentinization.

The second question is more problematic. Simply adding borate does not solve problems with the prebiotic formose synthesis of carbohydrates from formaldehyde. The synthesis begins with an exceptionally slow reaction between two $\mathrm{HCHO}$ molecules, a reaction that creates just single molecules of glycolaldehyde. The formose process therefore relies on the complex reaction cycles that use glycolaldehyde molecules (Hollis 2000) to "fix" more HCHO to give higher carbohydrates (Fig. 10). Unfortunately, intermediates in these cycles also have 1,2-dihydroxyl units that bind to borate. Accordingly borate (at $100 \mathrm{mM}$ ) prevents formose cycling, with $\mathrm{HCHO}$ disproportionating instead to give formate $\left(\mathrm{HCOO}^{-}\right)$ and methanol $\left(\mathrm{CH}_{3} \mathrm{OH}\right)$ as the dead-end products. Even at $6 \mathrm{mM}$, borate significantly slows formose cycling.

Obviously, the ability of borate to stabilize pentoses (such as ribose and arabinose) and pentuloses (such as ribulose and xylulose) is useless if borate prevents their formation. Thus, the second question asks whether processes exist that might form carbohydrates from $\mathrm{HCHO}$ in the presence of borate minerals without the slow reaction between two HCHO molecules, and therefore without the need to have all of the cycles shown in Figure 10.

One particularly promising cycle that is guided by borate was hypothesized (Fig. 13). It starts with dihydroxyacetone, which lacks a 1,2-dihydroxyl unit. This should, according to the hypothesis, enolize in the presence of borate and initiate a simple catalytic cycle to fix $\mathrm{HCHO}$ (reactions within the red dotted box in Fig. 10). Proceeding clockwise in Figure 13, the enediol of dihydroxyacetone should react as a

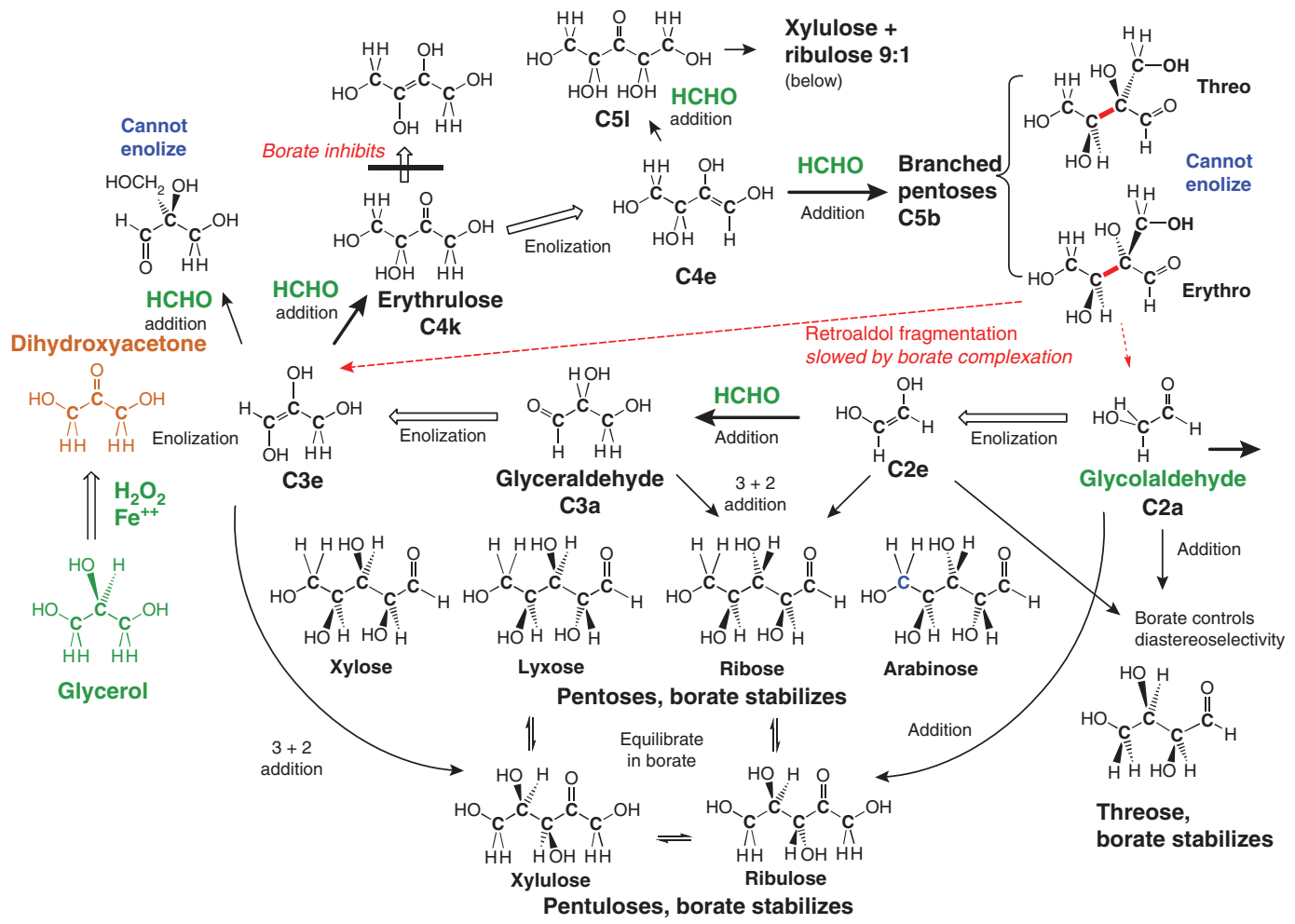

Figure 13. Borate-guided prebiotic path to form carbohydrates from formaldehyde. Compounds in green are known to be prebiotic. Compounds in blue cannot enolize. Dihydroxyacetone is shown in brown. 


\section{S.A. Benner et al.}

nucleophile with $\mathrm{HCHO}(\mathbf{C 1})$ to give erythrulose $(\mathbf{C} 4 \mathbf{k}, 3+1=4)$.

Erythrulose cannot form a cyclic hemiacetal as do pentoses (Fig. 11), and therefore does not bind borate tightly. It can, however bind borate less tightly through its 3,4-diol unit (Fig. 14). As the boron atom in the complex carries a negative charge, this binding should direct the enolization of erythrulose away from the borate to give the 1,2-enediol (C4e), which should fix a third $\mathrm{HCHO}$ to give either the linear or branched C5 species at the top (C5l) and topright $(\mathbf{C} 5 \mathbf{b})$ of Figure 13 by aldol reaction at the less or more hindered enediol carbon of C4e (these are both $4+1=5$ reactions).

The branched pentoses $\mathbf{C} 5 \mathbf{b}$ do not have enolizable hydrogens, and therefore cannot react as nucleophiles. They can, however, cyclize to give

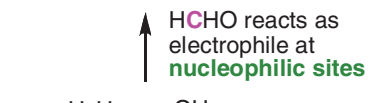

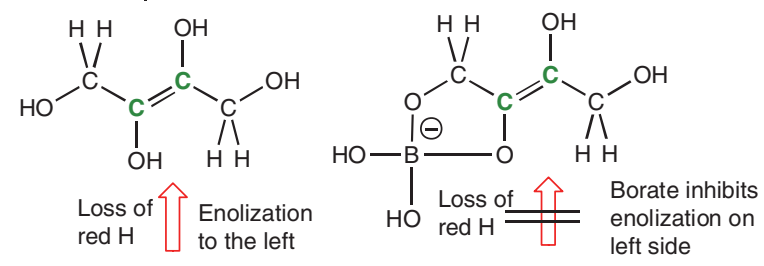

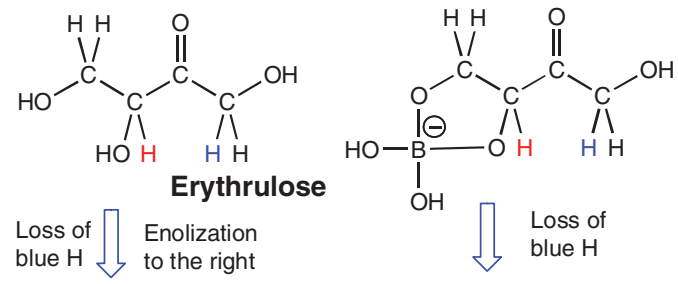<smiles>CC(O)C(O)C(O)(O)C(O)=CO</smiles><smiles>O=C(CO)C(O)CO</smiles><smiles>O=CC(O)(CO)C(O)O</smiles>

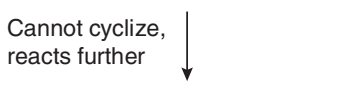

Cyclizes, binds borate,<smiles></smiles>

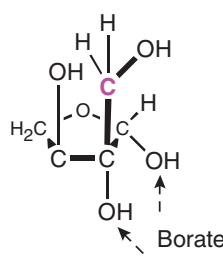

Figure 14. Binding of borate to the 3,4-diol unit of erythrulose should direct enolization to give the 1,2-enediolate, as this removes the $\mathrm{H}^{+}$from the carbon the farthest from the negative charge on boron. 
species that have adjacent 1,2-diol units that can bind borate. Therefore, their complexes with borate should accumulate. The uncomplexed branched pentoses $\mathbf{C} 5 \mathbf{b}$ species can, however, undergo retroaldol fragmentation to generate C2a and C3e (Fig. 13, $5=2+3$ ). The C3e is, of course the very same enediol that was generated from dihydroxyacetone, and can start the cycle anew. The enediol of newly formed glycolaldehyde $(\mathbf{C} 2 \mathbf{e})$ should react with $\mathrm{HCHO}(\mathbf{C 1})$ to form $\mathbf{C} 3 \mathbf{a}$ (a $2+1=3$ reaction), which is hypothesized to enolize to form enediol C3e, again the same enediol that is formed by enolization of dihydroxyacetone. Thus, we can go around the cycle again, fixing more $\mathrm{HCHO}$.

A rich collection of labeling experiments with $\mathrm{H}^{13} \mathrm{CHO}$ and $1{ }^{13} \mathrm{C}$-glycolaldehyde show that each of these steps is possible under conditions that might have occurred on early Earth (Benner, Kim, and Kim unpublished). These studies often use alkaline borate solutions buffered to $\mathrm{pH} 9$ to 11 by carbonate, which is available from atmospheric carbon dioxide. Formation of $2{ }^{2}-{ }^{13} \mathrm{C}$ and $4-{ }^{13} \mathrm{C}$ 2-hydroxymethylerythrose $(\mathbf{C} 5 \mathbf{b}), 2{ }^{2}-{ }^{13} \mathrm{C}-$ 2-hydroxymethylthreose (C5b), and linear $1-{ }^{13} \mathrm{C}-1,2,4,5$-tetrahydroxypentan-3-one (C5l) from $\mathrm{H}^{13} \mathrm{CHO}$ proceeds easily without human intervention in these buffers, a fact that was established by comparing carbon- $13 \mathrm{nmr}$ signals in the products with the signals of labeled authentic material obtained by direct synthesis.

These steps in the presence of borate can be examined individually to determine how robust they are with respect to changes in conditions. For example, if the concentration of glycolaldehyde is present in two-fold excess over $\mathrm{HCHO}$, addition of $\mathrm{H}^{13} \mathrm{CHO}$ to glycolaldehyde $(1+2$ $=3$, at $65^{\circ} \mathrm{C}$ ) followed by reaction with a second molecule of glycolaldehyde (in a $3+2=5$ reaction) gave $5-{ }^{13} \mathrm{C}$-ribose, $5-{ }^{13} \mathrm{C}$-arabinose, and $1-{ }^{13} \mathrm{C}$-xylulose as major metastable products. Reaction of glycolaldehyde (C2e) in the absence of $\mathrm{CH}_{2} \mathrm{O}$ gave four-carbon sugars, threose, and erythrose in $2+2=4$ aldol addition reactions. The formation of threose is significant because this tetrose can replace ribose in the backbone of RNA-like genetic molecules (Schöning et al. 2000; Ebert et al. 2008; Horhota et al. 2005). Consistent with their ability to form a cyclic hemiacetals that coordinate borate, threose, and erythrose are also quite metastable in borate buffers at $\mathrm{pH} 10.4$.

The same process can be observed with silicate. Silicate dissolves as its sodium salt only at high $\mathrm{pH}$; at lower $\mathrm{pH}$, silica precipitates. Nevertheless, a solution of concentrated sodium silicate (about 20\%, "water glass") has a $\mathrm{pH}$ of 11.5 to 12.0 . Even at 100:1 fold dilution, however, glycolaldehyde and glyceraldehyde react to form arabinose and other pentoses, which are also stabilized by complexation, this time to silicate (Lambert et al. 2004).

To complete the metabolic cycle, we begin by recognizing that the branched pentoses C5b are stabilized by borate, even though they suffer retroaldol fragmentations rapidly in the absence of borate (half life of ca. 30 minutes at $65{ }^{\circ} \mathrm{C}$ ). The half-life for the retroaldol fragmentation is ca. 24 hour at $40 \mathrm{mM}$ borate, and becomes still longer at still higher borate concentrations. Thus, on a prebiotic Earth in the presence of $\sim 200 \mathrm{mM}$ borate, branched pentoses formed from $\mathrm{HCHO}$ and glycolaldehyde and/or glycerol (Cooper, 2001) should have formed stable borate minerals. These, in turn, could have been reservoirs for subsequent steps in the prebiotic synthesis of RNA.

Of course, they could also support the cycle by slow fragmentation, or by fragmentation after they are stripped of borate by another carbohydrate (e.g. ribose) that binds borate more tightly. To demonstrate the cycle, $\mathbf{C 5 b}$ was incubated with $\mathrm{H}^{13} \mathrm{CHO}$ at $20 \mathrm{mM}$ borate. The mixture gives rise to labeled $\mathbf{C 5} \mathbf{b}$ as well as other products that can arise only if $\mathbf{C} 5 \mathbf{b}$ had suffered a retroaldol fragmentation to give glycolaldehyde and glyceraldehyde. This establishes the complete cycle.

These results show the possibility of a formaldehyde fixation cycle, where $\mathbf{C} 2$ and $\mathbf{C} 3$ add $\mathrm{HCHO}$ to give branched species that either accumulate or suffer retroaldol fragmentation to give glycolaldehyde and glyceraldehyde. These can either capture $\mathrm{HCHO}$ to go around the cycle again, or can combine to give xylulose and ribulose as stable borate complexes.

Under kinetic control, the ratio of C5 species formed depends on the relative rates of 
S.A. Benner et al.

aldol additions and fragmentations, the concentrations of various species, $\mathrm{pH}$ and borate concentration. However, under prolonged time on a primitive Earth, thermodynamics might well have determined the final products rather than kinetics. Equilibration within two sets of stereosimilar five-carbon species (ribulose, ribose and arabinose, and xylulose, xylose, and lyxose) is well known under a variety of mechanisms (Angyal 2001). Thus, a route that gives ribulose in the presence of borate also gives ribose, whereas a route that gives xylulose in the presence of borate also gives xylose. More slowly, the two pentose-pentulose sets themselves interconvert (Fedoronki and Linek 1967). Absent borate, the equilibrium ratios can be represented as a series (xylose 1:1 xylulose 85:15 ribulose 1:9 arabinose 4:1 ribose) (Sultana et al. 2003), with the ratio of any two C5 carbohydrates calculable by multiplying the appropriate ratios (thus the xylulose:ribose equilibrium is $\sim 5: 2$ ). Borate favors the -uloses in each set over the -oses; among the pentoses, borate complexation favors ribose (Mendicino 1960; Li et al. 2005).

\section{Challenges of Prebiotic Metabolic Cycling}

Interestingly, borate-moderated cycles such as those in Figure 13 share some features proposed for cycles hypothesized for "metabolism first" models (Shapiro 2007). Although the "genetics first" versus "metabolism first" models for the origin of life on Earth are currently being presented as adversaries (Orgel 2008), no logic compels them to be. It is nearly certain that chemical processes that might be likened to metabolism occurred on Earth before genetics, providing components of whatever genetic system did first emerge.

However, a cycle will not operate if more than one equivalent of material leaks from the cycle before completion of the cycle produces a second equivalent of cyclable material. Prebiotic metabolic cycles can easily be defeated by leakage that allows enough material to escape from the cycle to prevent product accumulation.

To understand leakage in mineral-controlled cycles, we might focus on leakage products that may have emerged from the hypothetical cycle in Figure 13. One leakage product is 1,2,4,5tetrahydroxypentan-3-one, shown the top of Figure $13(\mathbf{C 5 1})$. It is a linear species formed by the addition of HCHO to the erythrulose enediol (C4e) at its less hindered center $(4+1=$ 5). This species cannot form a cyclic hemiacetal to bind borate; it therefore reacts further in carbonate-borate buffer.

Remarkably, the leakage is "productive." With a half-life of 4-5 days, synthetic $1-{ }^{13} \mathrm{C}-\mathrm{C} 5 \mathrm{l}$ in carbonate-borate buffer gives 1- and $5-{ }^{13} \mathrm{C}$-xylulose (90\%) and 1 - and $5-{ }^{13} \mathrm{C}$-ribulose (10\%). Ribulose is known to be isomerized in the presence of borate to ribose. Thus, leakage by this route forms the products that one wants, but in a different way from the aldol addition of a glycolaldehyde and glyceraldehyde.

\section{More Mineralogy to Manage Carbohydrate Metastability}

As before, borate's ability to stabilize carbohydrates offers both good news and bad news. In particular, retroaldol fragmentation of branched pentoses C5b is slowed dramatically by borate. Prebiotic chemical scenarios often assume millions of years of time to manage slow reactions (a thermodynamic control scenario), and we can easily imagine scenarios where the accumulation of branched carbohydrate outruns the concentration of borate, leaving some unbound complexes to suffer retroaldol reaction to give ribose, which extracts a borate from a branched pentose to permit the transformative process to go to completion.

Further, the relative scarcity of boron has become an issue. For example, Hazen has suggested that borate minerals are "exotic," in part because they are concentrated in pegmatites whose contents may have required too much time took to accumulate (Hazen et al 2009). It is difficult to know in this context what "too much time" might be, as weatherable igneous borates should have appeared on the surface as soon as the planetary material separated and concentrated as long as there was aqueous rain, dry land, and dry valleys. 
Planetary Organic Chemistry and the Origins of Biomolecules

Accordingly, some geologists are more comfortable with silicate control than they are with borate control, even considering the fact that silicates, although more abundant, are less soluble in water than borate. Aluminates are also candidate coordinating species, also abundant but also rather poorly soluble (aluminate and silicate together form clay).

Nevertheless, other mineral forming species are known to coordinate carbohydrates, including vanadate, germanate, and molybdate (Schilde et al. 1994). These are also "exotic," and are more oxidized with respect to the mantle than borate, silicate, and aluminate. Thus, they are not likely to have been present on a reducing early Earth in abundance. They may, however, have been present in significant amounts at specific locales.

Balancing their exotic nature is some very interesting chemistry produced by these mineral components, especially at moderate $\mathrm{pH}$. For example, molybdate $\left(\mathrm{Mo}^{6+}\right)$ minerals at neutral (or slightly acidic $\mathrm{pH}$ ) catalyze a Bilik reaction, a rearrangement of a hydroxyl-carbonyl compound to give an isomeric carbonylhydroxyl compound (Petrus et al. 2001). This can convert branched tetroses such as $\mathbf{C 4 b}$ into erythrulose and branched pentoses such as $\mathbf{C 5 b}$ to linear pentoses (Fig. 15). In both cases, "dead end" products might be returned to the catalytic cycle or to biologically interesting species.

Indeed, incubating branched pentose (C5b) in the presence of molybdate $\left(65^{\circ} \mathrm{C}, 24\right.$ hour $)$ leads to an equilibrium mixture of $\mathbf{C} 5 \mathbf{b}$ starting material and linear xylulose, with some linear pentulose 1,2,4,5-tetrahydroxypentan-3-one (Kim and Benner, unpublished). The rearrangement is stereospecific; threo branched pentose gives ribulose. As noted above, xylulose and ribulose equilibrate slowly with $\mathrm{Mo}^{6+}$ to give xylose and ribose. A similar reaction was observed with $\mathrm{Ca}^{++}$as catalysts, but at high $\mathrm{pH}$.

The Need for Dry Land, Incompletely Reducing Conditions, and Incompatible Species

To exploit molybdate, the $\mathrm{pH}$ must fall. This could happen under a carbon dioxide atmosphere through dissolution of atmospheric $\mathrm{CO}_{2}$ in an

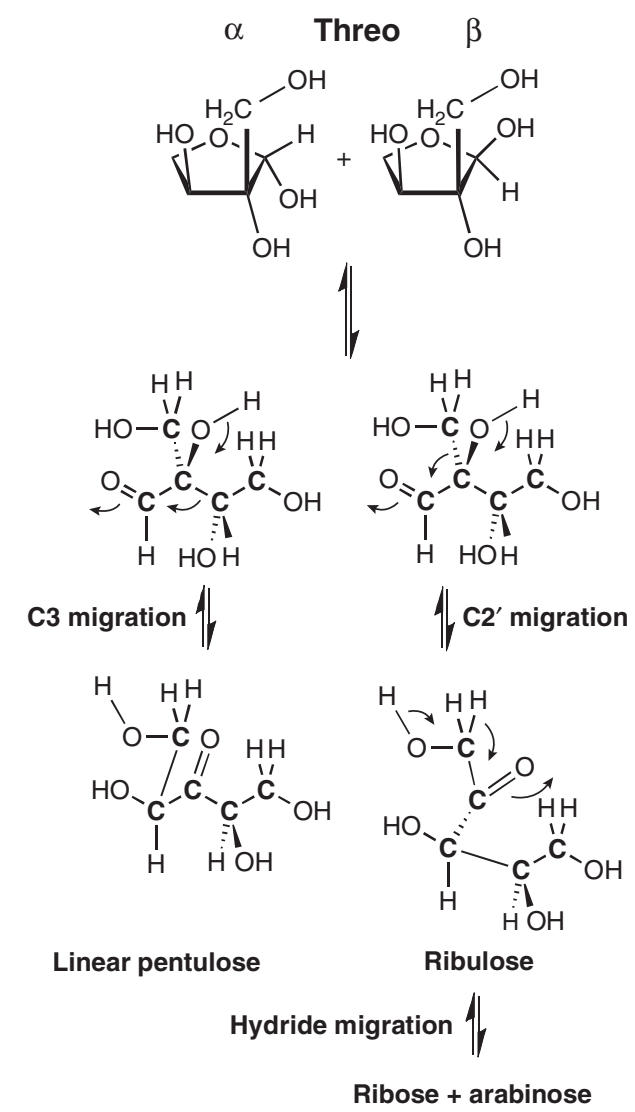

Figure 15. The Bilik reaction uses molybdate minerals to catalyze the stereospecific isomerization of carbohydrates such as the branched pentoses to give linear pentuloses such as ribulose at neutral $\mathrm{pH}$ under mild conditions.

alkaline solution. Thus, coupled with the borateguided (or silicate-guided or aluminate-guided) prebiotic fixation of $\mathrm{HCHO}$ and fluctuating $\mathrm{pH}$, $\mathrm{Mo}^{6+}$ can generate free ribose and xylose from C5b branched pentoses. This model envisions a borate-rich (or silicate-rich) alkaline stream emerging from serpentinizing igneous rocks above the Earth's surface, with formaldehyde arriving from the atmosphere above as the product of electrical discharge through a moist atmosphere dominated by carbon dioxide. Under these conditions, complexes of borate or silicate are formed with branched pentoses, ribulose and xylulose, and their corresponding pentoses, arabinose, lyxose, ribose and xylose.

The alkalinity of such a stream would be buffered over time by the dissolution of 
S.A. Benner et al.

atmospheric carbon dioxide. As the $\mathrm{pH}$ drops, the rate of formation of carbohydrates via enolization reactions slows, but so does their rate of decomposition. At the same time, borate complexes weaken and silicate precipitates, but molybdenum species capable of supporting the Bilik reaction become more abundant. According to this model, these conditions transform the branched carbohydrates to linear carbohydrates, which themselves form pentoses like ribose (Mendicino 1960). If the $\mathrm{pH}$ rose, the ribose would again become bound to and stabilized by borate. Such pH fluctuations would help equilibrium to be reached.

Certain models for early Earth are not compatible with this scenario, of course. For example, this scenario could not easily operate on a planet that was entirely flooded by water, as borate and alkali would be diluted into the planetary ocean whose oxidation state, $\mathrm{pH}$, and mineral composition would be that of the ocean as a whole. Dry land is needed to permit the concentration of borate and borate-organic evaporite minerals for this model; alternatively, compartmentalization is needed within the ocean, such as near subsurface vents, to have such cycles. Thus, if the "super-Earths" being observed as extrasolar planets are indeed "water worlds," this cycle would be more difficult to operate, requiring sequestration in specific suboceanic environments.

Given land surfaces, however, the model makes sense. Fluctuating $\mathrm{pH}$ is not implausible, as the high $\mathrm{pH}$ emerging from serpentinizing rocks is buffered beneath a $\mathrm{CO}_{2}$ atmosphere. Borate is readily delivered to alkaline washes through the erosion of tourmalines which were almost certainly present in igneous rock on early Earth, as they are today. $\mathrm{Mo}^{6+}$ is an oxidized form of the element, but not a strongly oxidizing form $\left(\mathrm{MoO}_{2}+\mathrm{H}_{2} \mathrm{O}+2 \mathrm{Fe}^{3+}=\mathrm{MoO}_{3}+2 \mathrm{H}^{+}+2\right.$ $\mathrm{Fe}^{2+}$ at $+236 \mathrm{mV} ; 2 \mathrm{MoO}_{2}+\mathrm{SiO}_{2}=\mathrm{Si}+2$ $\mathrm{MoO}_{3}$ at $-0.145 \mathrm{mV}$ ) Thus, that the formation of $\mathrm{MoO}_{3}$, which is hydrated to give molybdate, would have been favored at neutral when the ferric:ferrous ratio is one part in ca $10^{10}$.

Of course, other elements may be involved in such processes. Sulfur is an interesting example. Species containing sulfur interact with carbohydrates and other compounds containing $\mathrm{C}=\mathrm{O}$ bonds. Hydrogen sulfide attacks $\mathrm{C}=\mathrm{O}$ groups, just like water. Further, the bisulfite $\left(\mathrm{HSO}_{3}^{-}\right.$) anion reacts with $\mathrm{C}=\mathrm{O}$ units to form reasonably stable bisulfite addition products. Bisulfite is formed from sulfur dioxide, which was undoubtedly produced on early volcanoes on Earth.

The reaction of carbohydrates under plausibly prebiotic conditions in the presence of these other species has only begun (Weber, 2001). Much more research is needed before a model can capture the entire space of variable contents in a way that suggests what mixtures are productive and what mixtures are nonproductive, for prebiotic synthesis on a complex planet. Ultimately, compatibility issues need to be captured in a table that includes both organic and inorganic species, including cations and anions that are incompatiblewith solubility, redox potential, and reactivity.

\section{REFERENCES}

Angyal SJ. 2001. The Lobry de Bruyn-Alberda van Ekenstein transformation and related reactions. Glycoscience 215:1-14.

Benner SA. 2009. Life, the Universe and the Scientific Method. Gainesville FL, Foundation Press. 320 pp.

Bernstein MP, Dworkin J, Sandford SA, Cooper GW, Allamandola LJ. 2002. Racemic amino acids from the ultraviolet photolysis of interstellar ice analogues. Nature 416:401-403.

Blackmond DG. 2010. The origin of biological homochirality. Cold Spring Harb Perspect Biol 2: a002147.

Breslow R. 1959. On the mechanism of the formose reaction. Tetrahedron Lett 21:22-26.

Butlerov A. 1861. Bildung einer zuckerartigen Substanz durch Synthese. Annalen Chemie 120:295-298.

Cairns-Smith Alexander. 1982. Genetic Takeover and the Mineral Origins of Life. Cambridge UK: Cambridge University Press. 488 pages.

Chapelle S, Verchere J-F. 1988. A ${ }^{11} \mathrm{~B}$ and ${ }^{13} \mathrm{C}$ NMR determination of the structures of borate complexes of pentoses and related species. Tetrahedron 44:4469-4482.

Cleaves HJ. 2008. The prebiotic geochemistry of formaldehyde. Precambrian Res 164: 111-118.

Cooper G, Novelle K, Belisle W, Sarinana J, Brabham K, Garrel L. 2001. Carbonaceous meteorites as a source of sugar-related organic compounds for the early earth. Nature 414: 879-884.

Dyson F. 1985. Origin of life. Cambridge University Press. 94 pp. 
Ebert MO, Mang C, Krishnamurthy R, Eschenmoser A, Jaun B. 2008. The structure of a TNA-TNA complex in solution: NMR study of the octamer duplex derived from $\alpha$-(L -threofuranosyl-(3'-2'-CGAATTCG). J Am Chem Soc 130: 15105-15115.

Fedoronki M, Linek K. 1967. Transformation of pentoses in pyridine. Coll Czech Chem Comm 32: 2177.

Hazen RM, Ewing RJ, Sverjensky DA. 2009. The evolution of uranium and thorium minerals. Am Mineral 94: 12931311.

Hollis JM, Lovas FJ, Jewell PR. 2000. Interstellar glycolaldehyde: The first sugar. Astrophys J 540: L107-L110 Part 2.

Horhota A, Zou K, Ichida JK, Yu B, McLaughlin LW, Szostak JW, Chaput JC. 2005. Kinetic analysis of an efficient DNA-dependent TNA polymerase. J Am Chem Soc 127: 7427.

Joyce GF, Orgel LE. 1999. Prospects for understanding the origin of the RNA world. In The RNA world 2nd edn. (eds Gestland R. et al.). Cold Spring Harbor Press Cold Spring Harbor NY.

Kasting JF. 1993. Earth's early atmosphere. Science 259:920925.

Lambert JB, Lu G, Singer SR, Kolb VM. 2004. Silicate complexes of sugars in aqueous solution. J Am Chem Soc 126:9611-9625.

Larralde R, Robertson MP, Miller SL. 1995. Rates of decomposition of ribose and other sugars, implications for chemical evolution. Proc Natl Acad Sci 92:8158-8160.

Li Q, Ricardo A, Benner SA, Winefordner JD, Powell DH. Desorption/ionization on porous silicon mass spectrometry studies on pentose-borate complexes. Anal Chem 77: 4503. 2005.

Mendicino JF. 1960. Effect of borate on the alkali-catalyzed isomerization of sugars. J Am Chem Soc 82:4975.

Miller SL. 1955. Production of some organic compounds under possible primitive earth conditions. J Am Chem Soc 77:2351-2361.

Mueller D, Pitsch S, Kittaka A, Wagner E, Wintner CE, Eschenmoser A. 1990. Chemistry of alpha-aminonitriles Aldomerization of glycolaldehyde phosphate to rac-hexose 24 6-triphosphates and. in presence of formaldehyde. rac-pentose 24 -diphosphates: rac-allose 246 triphosphate and rac-ribose 24 -diphosphate are the main reaction products. Helv Chim Acta 73:1410-1468.

Orgel LE. 2008. The implausibility of metabolic cycles on the prebiotic Earth. PLOS Biol 6: e18.

Oró J. 1960. Synthesis of adenine from ammonium cyanide. Biochem Biophys Res Commun 2:407-412.

Petrus L, Petrusová M, Hricovíniová Z. 2001. The Bilik reaction. Glycoscience 215:15-41.
Pinto JP, Gladstone GR, Yung YL. 1980, Photochemical production of formaldehyde in Earth's primitive atmosphere. Science 210:183-184.

Pizzarello S, Shock E. 2010. The organic composition of carbonaceous meteorites: The evolutionary story ahead of biochemistry. Cold Spring Harb Perspect Biol 2: a002105.

Powner MW, Gerland B, Sutherland JD. 2009. Synthesis of activated pyrimidine ribonucleotides in prebiotically plausible conditions. Nature 459: 239-242.

Prieur BE. Étude de l'activité prébiotique potentielle de l'acide borique. C R Acad Sci Paris Chimie 4:667-670.

Sagan C, Khare NB. 1979. Tholins: Organic chemistry of interstellar grains and gas. Nature 277:102-107.

Sagan C, Khare NB, Bandurski LE, Batholomew N. 1978 Ultraviolet-photoproduced organic solids synthesized under simulated jovian conditions: Molecular analysis. Science 199: 1199-1201.

Sanchez RA, Ferris JP, Orgel LE. 1967. Studies in prebiotic synthesis II. Synthesis of purine precursors and amino acids from aqueous hydrogen cyanide $\mathrm{J}$ Mol Biol 30:223-253.

Schilde U, Kraudelt H, Uhlemann E. 1994. Separation of the oxoanions of germanium, tin, arsenic, antimony, tellurium, molybdenum and tungsten with a special chelating resin containing methylaminoglucitol groups. Reactive Polymers 22:101-106.

Schöning KU, Scholz P, Guntha S, Wu X, Krishnamurthy R, Eschenmoser A. 2000. Chemical Etiology of nucleic acid structure. The $\left\langle\right.$-threofuranosyl- $\left(3^{\prime} \rightarrow 2^{\prime}\right)$ oligonucleotide system. Science 290:1347-1351.

Shapiro R. 1987. Origins: A skeptic's guide to the creation of life on earth. Bantam Books, New York.

Shapiro R. 1988. Prebiotic ribose synthesis. A critical analysis. Origins Life Evol Biosphere 18:71-85.

Shapiro R. June 2007. A simpler origin for life. Scientific American 296:46.

Sultana I, Mizanur RMD, Takeshita K, Takada G, Izumori K. 2003. Direct production of D-arabinose from D-xylose by a coupling reaction using $\mathrm{D}$-xylose isomerase $\mathrm{D}$-tagatose 3 -epimerase and D-arabinose isomerase. J Biosci Bioeng 95:342-347.

Weber AL. 2001a. The sugar model. Catalytic flow reactor dynamics of pyruvaldehyde synthesis from triose catalyzed by poly-D-lysine contained in a dialyzer. Orig Life Evol Biosph 31:231-240.

Weber AL. 2001b. The sugar model. Catalysis by amines and amino acid products. Orig Life Evol Biosph 31: 71-86.

Weber AL. 2007. The sugar model: Autocatalytic activity of the triose-ammonia reaction. Orig Life Evol Biosphere 37: $105-111$.

Zhai M, Shaw DM. 1994. Boron cosmochemistry Part I: Boron in meteorites. Meteoritics 29:607-615. 


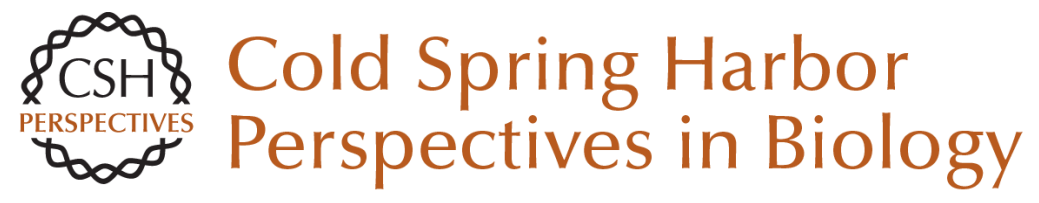

\section{Planetary Organic Chemistry and the Origins of Biomolecules}

Steven A. Benner, Hyo-Joong Kim, Myung-Jung Kim and Alonso Ricardo

Cold Spring Harb Perspect Biol 2010; doi: 10.1101/cshperspect.a003467 originally published online May 26,2010

\section{Subject Collection The Origins of Life}

Constructing Partial Models of Cells

Norikazu Ichihashi, Tomoaki Matsuura, Hiroshi Kita, et al.

Ribonucleotides John D. Sutherland

Deep Phylogeny--How a Tree Can Help

Characterize Early Life on Earth

Eric A. Gaucher, James T. Kratzer and Ryan N. Randall

Cosmic Carbon Chemistry: From the Interstellar Medium to the Early Earth Pascale Ehrenfreund and Jan Cami

Origin and Evolution of the Ribosome George E. Fox

Planetary Organic Chemistry and the Origins of Biomolecules Steven A. Benner, Hyo-Joong Kim, Myung-Jung Kim, et al.

Mineral Surfaces, Geochemical Complexities, and the Origins of Life

Robert M. Hazen and Dimitri A. Sverjensky

Historical Development of Origins Research Antonio Lazcano
The Hadean-Archaean Environment

Norman H. Sleep

An Origin of Life on Mars

Christopher P. McKay

Primitive Genetic Polymers

Aaron E. Engelhart and Nicholas V. Hud

Membrane Transport in Primitive Cells Sheref S. Mansy

The Origins of Cellular Life Jason P. Schrum, Ting F. Zhu and Jack W. Szostak

From Self-Assembled Vesicles to Protocells Irene A. Chen and Peter Walde

The Origin of Biological Homochirality Donna G. Blackmond

Earth's Earliest Atmospheres Kevin Zahnle, Laura Schaefer and Bruce Fegley

For additional articles in this collection, see http://cshperspectives.cshlp.org/cgi/collection/

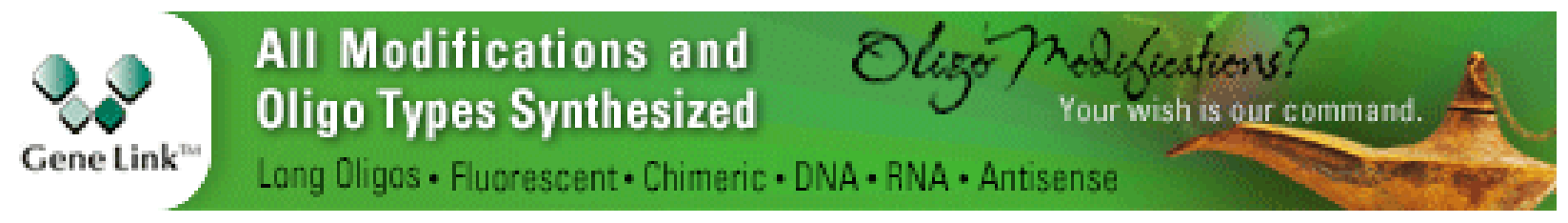

Copyright @ 2010 Cold Spring Harbor Laboratory Press; all rights reserved 